\title{
Analytical Overview on Some Factors that Affect the Development of Electronic Literature in Mali
}

\author{
Abdoulaye M'Begniga ${ }^{1}$, Yang Bo Ling ${ }^{2}$, Sissoko Bourema ${ }^{3}$, Muhammad Asif ${ }^{4}$ \\ ${ }^{1}$ School of Literature, Anhui Normal University, China \\ ${ }^{2}$ School of Journalism and Communication, Anhui Normal University, China \\ ${ }^{3}$ School Social development, East China Normal University, China \\ ${ }^{4}$ School of Journalism and Communication, Hunan Normal University, Changsha, China.
}

Correspondent Author: Abdoulaye M'Begniga

Email: ambegniga@yahoo.fr

\begin{abstract}
With the development of new information and communication technologies, including digital and Internet, literature has undergone profound changes in the past three decades. This is an opportunity to update practice and form. After completing experiments related to digital media for the first time in the 1990s, today's online literature provides a series of exciting opportunities to experience, and these experiences have begun to become the subject of university research. Electronic literature is a collection of computer-assisted literary creation. Like the rise of information and communication technology, it has affected almost all areas of life. Electronic literature has now become a reality. The development trend of electronic literature is already a range that needs to be considered, especially how to increase interest in reading and literature. Unfortunately, electronic literature generally lags behind in West Africa, especially in Mali. Therefore, this article analyzes the electronic literature of Mali. The research method used by the author in this article is the literature review which consisted of the analysis of different articles, both on the internet and papers written by other researchers on the same topic. Also, for a better analytical approach in the framework of writing this article, The author considered it necessary to adopt the theoretical research approach, while secondary information was acquired by examining numerous relevant sources. This state of affairs led the author, through the judicious and relevant analysis of these important academic sources on this same topic, to the conclusion that Mali, due to certain factors, lags considerably behind in the field of electronics literature that is becoming more and more fashionable.
\end{abstract}

Keywords: electronic, literature, internet, Mali, analysis.

\section{Introduction}

In his paper titled "Cyber-Literature: A Reader - Writer Interactivity", Rahman, F. (2017) defines literature in these terms:

"Literature is a reading that contains elements of entertainment, education, and information. It is an author's creative work poured in beautiful language. Literature stimulates the sensitivity of its readers. It presents various aspects of life and even constantly parses life, or may be, a reflection of life. Literature was born since humans inhabit this earth. Even since before humans know writing system, literature has already become the part of human life. Literary works are a part of the culture. As a cultural product, literature develops in line with the development of human life."
Representatives of English literature in the seventeenth century include Shakespeare, Webster, Marwell, and Milton; it also includes Bacon's prose, John Dunn's, Bunyan's autobiography describing the inner world, and Sir Thomas Brown He wrote an indescribable work. Horchs' Leviathan" might be included. (Terry Eagleton, \& Chen Jianhui, 1992).

Now because of the website and the emergence of social software like blogs, many writers appear on the Internet. Writing reappears in popular life in a more democratic way. In addition, electronic literature is more sensitive to the presence of readers. Now, readers are invited to the writer's studio every day and let them read their manuscripts. The use of computers as a writing 
medium strengthens the understanding of technological determinism, which is also a basic script, but due to the relative complexity of word processing software, the importance of technological determinism is more obvious. On the one hand, computer writing has given people new freedom and the text is more plastic; on the other hand, the design of programming literature allows its creators to satisfy the constraints related to algorithm laws. (RUCAR, Yan, 2015) In fact, electronic literature can potentially refer to two different things, depending on the specific meaning that the person citing it wants to express. The most specific meaning refers to literature or written works of literary value created in digital media, which use simple formats other than written text.

The types of these works are "natural numbers", not just text scanned and printed in digital format. Electronic documents can refer to literary works that have been converted into digital format, and this usage is becoming more and more popular. The main feature of electronic literature is that it is created in a digital format using electronic media. Although someone can insert a text file in a word processing program, this does not necessarily constitute a true electronic document, it is just a digital copy of the text. Proponents believe that as an independent form of literary works, electronic literature should be created by taking advantage of the difference between digital media and standard print media. This can be achieved in a variety of ways. Electronic literature can be accessed through an e-reader. Someone can write a poem, and he can create it as a digital animation instead of simply printing it out in a document. Use digital media to create poetry for readers. Poetry exists in the form of electronic literature outside of printed text. Other media forms that can take advantage of these advantages include written works created on Internet sites, interactive media with powerful literary elements, and Stories delivered via e-mail, short message service (SMS) or short message. "

On the other hand, the rise of information and communication technology has affected almost all fields, including education. Literature is not excluded, because today electronic publishing has become an unquestionable reality. However, this reality is not the same in all parts of the earth. The reality is that some areas on the planet are unfortunately lagging behind. This is the case in West African countries where French is the official language. Although it performs well in French literature, it has not achieved good results in the field of electronic literature.

"When the ELO decided to put the collection together, their organizing keyword was "variety". To interact with the sixty pieces is to experience their success in developing an enticing anthology particularly for course syllabi in electronic literature. The collection includes poetry, drama, and fiction rendered with sound, animation, and of course, that golden trait, "interactivity". The pieces use Shockwave, Flash, JavaScript, interactive programming languages (TADS and Inform) and HTML. The works are hyperlinked texts, animated poems, games, films, and new genres that have yet to be contained in any tidy taxonomy. The question "What is electronic literature?" quickly gives way to "What isn't?" as these editors produce not so much a genre as a network of pieces whose greatest common factor is their delivery media, the CD-ROM or the Internet." (Marino, M. C. (2008)

Regarding electronic literature, reference can be made to its founding history to that of ELO. Pawlicka, U. (2017) states that Electronic literature has expanded its limits, going beyond issues of definition, genre, and poetics, and developing into something more than literature. In his paper titled: "Electronic Literature as Paratextual Construction" Friedrich W. Block, in relation to electronic literature, wrote: "In contrast to the short, sober information found on the ELO-history-page about its foundation, Scott Rettberg (2012) writes a major story published in the journal Dichtung Digital relating to the ELMCIP project (Electronic Literature as a Model for Creativity in Practice). The title sounds like a confirmation of my first thesis: "Developing an Identity for the Field of Electronic Literature." First of all, the story is about the history of the ELO, and the narrative begins with the hour of its birth during theTechnology Platforms for 21st Century Literature conference held at Brown University in 1999: "During the conference banquet," Rettberg reports, "I found myself sitting at a table with Coover and Ballowe (...)", and he recalls how he outlined his ideas:

(...) to find ways to support the new art forms and to apply some capital to the situation of experimental literature (...) I could see the usefulness of a non-profit organization for electronic literature, modeled to some extent on existing literary non-profit organizations. To my surprise, both Ballowe and Coover embraced these ideas.” Block, F. W. (2018)

In her paper titled "Towards a History of Electronic Literature", Pawlicka, U. (2014) asserts that history of electronic literature can assist scholarship and the teaching of literature because "literary history makes evident diachronically the great and extremely complex connections between periods in time "(Pope xvii). Owing to the structures and practice of new media, the development of electronic literature from its inception as computer literature to web-based literature has aspects different from printed literature. That a history of electronic literature is not only relevant, but that it is necessary can be seen in the work of digital humanities scholars such as Alice Bell, N. Katherine Hayles, GeorgeP. Landow, Lev Manovich, or Marie-Laure Ryan who in many instances refer to aspects of the history of electronic literature ("electronic" literature is also termed at times as "digital" literature). At the same time, electronic literature is changing as a consequence of the development of technology and its uses more rapidly than print literature did.

In addition, it is important or even necessary to speak of cyber-literature which, in a certain way, has a narrow or even similar reference to electronic literature. Indeed, there are a number of terms that are used so far for cyberliterature, among others there is literary machine (Nelson, 
1993), cybertext (Eskelinen, 2012), digital literature (Hoover, et al. al. 2014), digital media (Ryan, 2013), digital literature (Sanz, 2007) and electronic literature (Hayles, 2001).

Moreover, it is important, even necessary to insist on the evidence that Mali, like many other West African countries, is at the same time a country of writings, of writing and above all of literature as such.In his paper, entitled "WRITINGS AND WRITING IN WEST AFRICA", this is what Cissé, M. (2006) tries to elucidate when he asserts that in West Africa, and more precisely in what is commonly called the Sudano-Sahelian zone, contacts between the local population and the ArabMuslim culture date back to the 8th and 9th centuries AD. Archaeological excavations carried out in Gao have uncovered inscriptions in Arabic dating from the 11th century. They made it possible to authenticate and date with certainty the meetings between the inhabitants of the Sudano-Sahelian zone and those of the Arab-Muslim culture. The desert has never been an obstacle for transSaharan trade. Arab travelers and geographers, better known under the name of Taariikh chroniclers, report that during the 11th century West Africa experienced an influx of people of Berber origin, the Zanaga. It was through these first direct contacts that part of the West African population became Muslim under the influence of their Almoravid brotherhood. The Almoravids were during this period the linchpins of Islamization in the SudanoSahelian zone. From these contacts, most of the languages of West Africa have borrowed from Arabic as well as from Berber many terms, including the days of the week, some polite expressions and the Hegira 2 calendar. the most important phenomenon is the adoption of Arabic letters to write African languages, such as Fulfulde, Mandingo, Hausa and Wolof, to name a few. The first attempts at writing indigenous African languages were certainly the prerogative of a class of literates in Arabic mainly composed of Muslim scholars and some members of aristocratic families. We consider it necessary to make this historical precision concerning the literature in West Africa, more precisely that of Mali, whether it is Arobophone or Francophooone, it is with the intention of emphasizing the importance and the need for he electronization of this literature insofar as electronic literature that some also call cyber literature has become a trend with the advent of the internet, but also the rapid development of new information technologies.

Moreover, Mali is one of the countries whose bibliographic system is the least efficient, the least developed in the world. Some of these countries are completely deprived of any form of bibliographic system, while in others, even if this system exists, it is very badly structured, very badly organized because it does not benefit from the necessary support of the share of political decision-makers. Few of these countries have a national bibliographic agency in the proper sense of the term. In most of these countries, it is the national libraries which "perform" some or all of the functions normally performed by national bibliographic agencies, in addition to their own. Consequently, the difficulties multiply because these national libraries do not have logistical and human resources - proportional to the complexity of the tasks entrusted to them. Some of them have also recognized their inability to cope with the many tasks entrusted to them. Added to these issues raised, the lack of digital infrastructure which is becoming more and more important, necessary while modernizing our society in all aspects, in all its dimensions. It is as much to affirm the obviousness that the digitization of libraries and other bibliographic structures is also an important aspect in the promotion of electronic literature. To perpetuate this literary wealth which has a very old history and which we mentioned previously, the promotion of electronic literature, which is undeniably a trend nowadays, is a sine qua non duty for the Malian authorities. Also, the endowment of the country of telecommunications infrastructures is essential within the framework of the promotion of electronic literature that some call cyber literature too.

\section{Definition of some concepts}

In this part, in order to provide readers with certain readability related to this article, to give definitions of certain concepts is very important and even necessary. To this end, we will give their definitions. These include:

Electronic: Related to electronic products, or operate according to its principles.

Computer and electronic technology: Although computing is a science, electronic technology is its popular opponent. For Milad Doueihi (2013), electronic technology itself is a culture based on it, but it transcends it because it exists in all levels of society, whether it is in the public or private sphere. As Marcelo Vitali Rosati said: "This explains the strict meaning and main usage of the word 'electronics'. This sampling and discretization process is the basis of all electronic technologies. These electronic technologies it operates from discrete numbers based on 2, that is, from a series of numbers between 0 and 1. Specifically, like a circuit, current passes (1) or current does not pass (0). On the one hand, the use of the term "electronic culture" and the development of its social and cultural values are first determined by the birth and proliferation of the Internet, more precisely, by the birth and proliferation of the Internet. That is to say, since 1990, the network, not just the existence of ord promoters, has determined major changes in our practice and our relationship with the world, because it has produced a new generation, dissemination, and acceptance of general knowledge model. As the Internet is everywhere in our lives, numbers are everywhere. Decades ago, computer technology was regarded as a powerful tool with multiple functions, able to help people in many areas of industry and cultural production. (VITALI-ROSATI, Marcello, 2014) On the other hand, a computer is an electronic machine that can receive and record information. In addition, it can process this information according to the programs recorded in the machine. These programs allow the screen to be sorted, copied, erased, edited, displayed, Display information in graphics or other forms, send it to 
a printer, control another machine, etc. In terms of digital information, these programs can perform a lot of calculations at lightning speed.

French-speaking countries: The definition of French terms proposed by Onesime Reclus is inclusive, and the definition of French words is "all those who are destined or seem to continue or become participants in our language" (Reclus, p. 422). In a broader sense, the word is semantically related to the subject of this article. It refers to the entire French-speaking world, that is, different countries and regions where French is the mother tongue or second language. It is a geographical expression and a geopolitical group. In addition, after defining the concepts contained in the title of the article, in order to make the article as easy to understand as possible, it is still important or even essential to introduce some concepts that are relatively directly or indirectly related to the subject of the article. These include:

Electronic publishing: First of all, it is important to emphasize this point traditionally; the three main bodies corresponding to the three main tasks of publishing constitute the characteristics of publishing: content selection, content legitimization and its dissemination. (VITALI-ROSATI, Marcello (dir.); SINATRA, Michael E. (dir.), 2014) "Electronic publishing includes any activity that uses contemporary electronic technology to design and shape digital content. With the advent of electronic technology, the evolution of editing practices is reshaping the entire process of knowledge production, content verification, and knowledge dissemination. We are seeing new things. The emergence of writing and reading tools and practices, and a change that is more global than culture."

\section{Motivation for choice of the topic}

We are very interested in the popular theme of "Electronic Literature In the French-speaking countries of West Africa: Overview on the case of Mali" because this theme is related to a hot issue in the literary world, namely "electronic literature". There are several factors that motivate us to think about electronic literature. At present, due to the emergence of technology, electronic literature has become a meaningful trend in the literary world, not only at the national level, but especially at the international level. In this regard, it deserves special attention. By choosing this topic, we believe that not only the need to consider the main role of electronic literature in promoting reading and the love of literature, but also the need to consider this new literary trend, which, due to the development of technology and the emergence of computers, has been projected into the future world of literature. In view of this, we promise to provide reliable sources of information and show sincerity and credibility in this newsletter. Our analysis motivation is based on the fact that some authors and organizations have dealt with issues related to electronic literature and heard it from multiple angles. Some people are interested in analyzing data about the rise of this literary trend. The question they ask is: Is there electronic literature? What is its prospect?
Others discuss the status quo, progress, and prospects according to the specific conditions of their respective countries. When discussing this topic, we have the responsibility to assess the situation in a particular geographic area, namely in French-speaking West Africa, especially Mali, where literature has had an impact and has made amazing progress since independence. Therefore, the French-speaking West African countries in general, and Mali in particular, must be interested in this new literary trend, which seems inevitable given the evolution of technology.

\section{Background and problematic}

In some special cases, the library attendance rate may generally be affected by strict measures promulgated by the competent authority. For example, Covid-19 is clear evidence throughout the world that even during curfews or wars, traffic is very limited or almost impossible. On the other hand, promoting reading through the construction and promotion of electronic literature is still a major challenge to improve the quality of education. In terms of better school curricula, reading as the core of literature is also an important pillar and remains a major challenge. It plays an important role in education and personal training. Therefore, it is very important to provide material conditions to obtain resources such as libraries. In other words, online and offline electronic libraries can be promoted to make it easier for people to obtain literary resources. However, in most African countries, most schools do not have libraries. Especially in Mali, like most demographic transition countries, the population of Mali is mostly composed of young people. The scarcity of libraries has had a serious negative impact on the entire intellectual circle, especially the young class. Some people say that the future of any society is young people. This young man must be an educated young man who is constantly evolving. Its education depends on material conditions. The impact of reading on young people is as important as the impact of education on young people.

\section{Objective}

The main purpose of this article is to evaluate electronic literature in Mali on the one hand, and to ensure that the authorities pay attention to the importance and usefulness of electronic literature, especially when new technologies emerge and become obvious reality. In other words, in this sense, the future world is a virtual world, and everything will be connected to technological machines such as computers. Therefore, in the "discussion" part of this article, we will try to answer the following questions:

$>$ With the rise of information and communication technology, can electronic literature be promoted in Mali?

$>$ In any society, reading is still the main pillar of teaching and education. Can electronic literature play a role in promoting reading? If so, how much influence will it have?

$>$ In the context of promoting electronic literature, what should be done? 
$>$ Finally, does electronic literature have a future in Mali?

\section{Methodology}

The method use by the author for this article is mainly literature review, articles and books that we download from the Internet. Insofar as this is not a paper requiring a field survey, we decided to conduct a literature review concerning the various documents on the topic. Thus, after the intellectual and meticulous analysis of these various documents, we proceeded to our analytical criticism.

\section{Discussion and analysis}

In his article entitled "This book which is not one: the electronic literary text" Bennett, G. (2010) edifies us not only on the advent of electronic literature, but also and especially its impact on oral texts in that it has enabled them to be digitized over time. It is a very positive impact vis-à-vis these oral texts in the sense that they were able to find a very large readership. These are, of course, oral texts that may have been put in books, and therefore printed.

"The twentieth century saw the birth of new textualities which seemed to be able to do without the book and which therefore hinted at the possibility of a literature independent of the printed page. Among them an oral textuality was announced from the first years of the century and it has not stopped developing since. Even the most performative oral texts, however - whether they be the sound poems of the historical avant-garde or the more recent spoken word and slam poems - have not always been able to resist the gravitation of the book, ending sooner or later with get printed. Conceptual texts have done little better: object-books, like artist's books, despite the unusual forms they can take and the motley objects they can contain, have never managed to stand out completely. of the book they claim to be, in name if not in form, while trying to go beyond it. More recently, the phenomenon of the new "e-books" and "iBooks" offers us digitized literary works, but basically they are only traditional texts camouflaged as digital "books", the text itself not differing from the texts. conventional since the new functionalities with which it is equipped (enlargement of the characters, possibility of making global searches, etc.) come from its support and not from its textuality. In this, the new "electronic books" are reminiscent of the old ones, namely the "Expanded Books" published by the Voyager company in the early 1990s and which few remember (and which no one reads any more) today. As for the current "augmented books", they are in fact printed books enriched with multimedia additions and social media functions which the reader can access online; they therefore remain firmly established in print despite their digital attributes. Of all the alternative textualities from the twentieth century and the beginning of the twenty-first, to my knowledge only one has managed to escape the printed page: that of the electronic literary text."

Literary effects can have a positive impact in the context of computer practice reassessment. We can emphasize that electronic literature is the result of these literary effects. In fact, the interaction between the body, the machine and the intermediate dynamics between them has produced important emerging phenomena, which help to understand the influence of electronic literature. (Hayles, N. K, 2008)

Electronic literature is an important literary trend that has long appeared in new information and communication technologies. Electronic literature has not only become a literary trend that interacts with the body, machines (computers), authors and readers, but also has become a core, important and key factor in promoting reading. In general, the emergence of new information and communication technologies is a positive factor for the development of literature. Some writers, such as D Hicks, even use the term "new horizons of literature." (Hicks, D, 2008).

\section{Overview on some countries where electronic} literature is very developed

In many countries in the world, such as China, electronic literature is booming. Electronic literature not only contributes to the promotion of literature, but also helps to promote reading. Reading is a key element of personal training. Some data will allow us to provide some clear details. In China, electronic literature has developed very rapidly, and network literature has achieved great success. Therefore, in the Hangzhou opening ceremony of the second China Cyber-Literature Week in May 2019, there were reports that: "Chinese Cyber-literature has developed rapidly in just 20 years and has become a vibrant part of Chinese socialist literature. Cyber-Literature should not be the literature of money, and the value of excellent online literature writers should not be judged by the amount of money. It is necessary to have a deeper understanding of the relationship between literature and the times, the people, and the great rejuvenation of the Chinese nation, and the social value, putting social benefits in the first place is the fundamental prerequisite for the continued prosperity and development of Chinese online literature.

Statistics from the "Blue Book" show that realistic subjects account for more than $60 \%$ of the new works released by major online literature platforms in 2020 . Among them, the reading time of Chinese online patriotic works has increased significantly, and the authors of Migu Literature pay more attention to people's livelihood topics, and the actual themes of Palm Reading Literature, Zhulang.com, and Hongshu.com have achieved remarkable results.

In addition, in the event titled "20 Years of Chinese Cyber-Literature in 20 Years and 20 Works" held in Shanghai, experts used these terms to say: "Without reform and opening up, there would be no development and prosperity of Chinese Cyber-literature. Chinese Internet literature is China One of the fruitful cultural achievements of the forty years of reform and opening up. Reform and opening up has created a large team of online authors and "netizen" readers, inspired the cultural originality of the Chinese people, nurtured and developed 
the cultural industry, and created good online literature ecology. Promoting the healthy development of online literature. For online literature, the most important thing is to stick to the development of socialist literature with Chinese characteristics, perceive the new era, grasp the new era, reflect the new era, create a new era, and continue to introduce masterpieces of online literature. Classic work, word-of-mouth work, and handed down work.

Today, in the field of online literature, China ranks first in the world. This is confirmed by numbers. In fact, according to the latest data, among the 731 million Internet users in China, online literature users have reached 333 million, accounting for $45.6 \%$ of the total number of Internet users. There are 304 million Internet users reading literature on mobile phones. Hundreds of literary websites have a total of 200 million Chinese characters updated daily, and the average daily page views of literary web pages exceed 1.5 billion. In 2016, the output value of China's online literature market exceeded 500 billion yuan. In just one reading group, 4 million authors upload original works for it every day, and the stock of online novels reaches tens of millions. Books transformed and published from online novels, film and television works, games, animations, audio books and peripheral products adapted from them have ignited the mass entertainment market and created a huge "Internet +"industry. It can be said that such a prosperous literary situation is unprecedented in Chinese history and unique in the world. Xu Tenglong, \& Hua Yan. (2020) (Tuo Jiguang. (2017).

Obviously, this huge success in the field of online literature is an obvious sign of the healthy development of Chinese electronic literature. It is worth noting that China has made considerable progress. In other words, China's great success in online literature did not happen overnight. This success is the success of a long journey. It seems that there is no interest in comparing Mali and China from the field of electronic literature, because the gap between the two countries is quite large. However, a closer look at China's approach can serve as an example, and it can be a model for Mali to promote its electronic literature. Internet literature in China is constantly developing vigorously, and now it has a large volume, and it is also a relatively familiar type of literature for the public. Although there is a huge gap in electronic literature between the two countries, Mali can still draw inspiration from China to promote the development of its own electronic literature.

Besides China, there are many other countries that have achieved great success in electronic literature, such as the United States, Latin America, and some countries in Europe. In some African countries, electronic literature is also experiencing vigorous development, even if it is relative. As far as electronic literature in the United States is concerned, we can say that electronic literature was born there. In fact, "The Electronic Literature Organization was established in 1999 to cultivate and promote the development of reading, writing, teaching, and understanding of literature and to persist in the everchanging digital environment. ELO is a 501c (3) nonprofit organization that includes writers , Artists, teachers, scholars and R\&D personnel. The Electronic Literature Organization (ELO) was founded by Scott Leitberg, Robert Coover, and Jeff Balloway. It was established in Chicago in 1999 and served as Balloway. The first chairman, Reitberg, served as executive director. During this period, ELO decided to accept, together with hypertext narratives and novels, emerging forms of electronic literature, including interactive narratives, online poetry, and others. At dot.com corporate under the sponsorship, it changed its direction very early. After the dot.com crash and 9/11, it moved to the University of California, Los Angeles under the guidance of the famous media theorist N. Catherine Hales, where it got the California UCLA English, SINAPSE and Design Support/Media Arts Department. In 2002, the first conference "State of Art" was held at UCLA."

Regarding electronic literature in the United States, Richard Haworth, chairman of the American Booksellers Association, said in response to a question about this new literary trend: "Everything widely publicized on television and media is not conducive to true literary creation." According to the data from the Industry Research Group, 50,000 books were published in the United States last year, with total sales of 23 billion U.S. dollars." (Rettberg, S. (2009)

Regarding European electronic literature, we are focusing on French. In fact, in France, in the collection of French Internet goals implemented within the framework of legal deposits on the Internet, we attach great importance to contemporary French online literature: more than 1,000 blogs and websites of contemporary French or French writers, dozens of online magazines and reader blogs, Hundreds of Twitter accounts were collected like this. Many such sites no longer appear online, such as Zazieweb, one of the pioneer sites for literary news. For those who are still online, the archive makes it possible to understand their evolution, which is particularly valuable for labyrinth sites, such as François Third Book or Philip De Jonkerhill disorder.

With regard to electronic literature in Latin America, author Taylor and Claire gave us an overview. In his book "Electronic Literature in Latin America" he highlights an Argentine writer who has always been very interested in electronic literature: "Marina Zebarini is a famous Argentine artist who has worked in many media, contains paintings, objects, and installation art. Several of her works belong to the category of electronic literature and involve narratives, such as her twins/non-twins. Reader reviewers can submit their own texts, images and sounds. This year, a "non-linear Internet narrative" (Zebarini) created and used Flickr (a glyph plotter) to leave the sediments taken every day in a cup of coffee, as well as short excerpts extracted from daily predictions of Internet constellations. Many of her recent work are installation works , Including "sound work in network code", an electronic device that combines the satellite image 
projection of the city of Buenos Aires with audio files and user interaction, in which the rope is suspended in the space as an interface for the user to play work." (Taylor, C., 019) Considering the current literary trend of electronic literature, she has worked on many literary works. Therefore, she has put many of her works online, which her fans can easily access.

Although Mali has a long way to go in promoting electronic literature, it can draw inspiration from China, Western countries, and many countries in Latin America and Africa that have made great progress in this regard. To achieve this, a lot of improvements are needed. Starting from the promotion of new technologies and communication technologies, this is a necessary condition.

In a colloquial society, it may be more inclined to speak and demonstrate than those in written societies. However, as Matthew Mermoud (2003) emphasized: "Words are the creators of human society: they form the basis of speech." Whether written or spoken, there is always a primitive in speech. (Dembele, Alexis, 2015)

Africa is a continent deeply rooted in oral literature. This is a continent of oral tradition. The society is considered to be an oral society and people tend to speak a lot. Oral expression has a high status. Especially in French-speaking West Africa, the status of spoken language in African society is of vital importance. In view of this social and traditional reality, compared with Western countries, reading culture is not firmly rooted in the habits of West Africans. This also confirms that considering the status of language, there is no point, that is, if you cannot conduct serious research on African culture.

In addition, speaking of literature is equivalent to speaking of written literature, so reading is also part of electronic literature, and Mali is no exception. In fact, in Mali, all the components of electronic literature are in a relatively backward position. This is caused by several factors:

\section{Electronic publishing is not developed}

The reality is very sad. The publication of paper books has fallen behind let alone electronic publishing. However, Mali can still take appropriate measures to promote the publication of paper books, and then promote the publication of e-books, which is essential to promote the development of e-literature. Visitors who observe electronic publishing in sub-Saharan Africa believe that the first reality is that electronic publishing is still in its infancy. In Europe, according to a 2017 report entitled "European Book Industry in 2017" by the European Publishers Federation (EFF), the book industry has 150,000 employees, a market capitalization of 30-40 billion euros, and e-books accounted for the total of $24 \mathrm{EU}$ countries. $6 \%$ to $7 \%$, Denmark accounted for $18 \%$, and France accounted for 3\%. The harsh observation shows how neglected this profession is in Africa. (Moustapha Mbengue, Moussa Samba, 2020)

Especially in Mali, electronic publishing is in its infancy. Regarding electronic publishing in developing countries, we can cite (Duval, 2015), electronic publishing in sub-Saharan Africa and the Arab world (Mitchell, nd), the post of African libraries in the electronic age: "Beyond their walls", (Dan, Bona, Ouattara, Brelovda, \& Baron, 2014), Sub-Saharan Africa School Digital Publishing Progress Report, is Africa ready for e-books? And (Finxian, 2013), Africa and e-books. Similarly, (Duval, 2015) tried to analyze the situation of digital publishing in Africa based on Kulez's research.

Duval put forward some obstacles that hinder the development of digital publishing, including language barriers, human factors and weak infrastructure. Therefore, the government needs to develop specialized infrastructure. The obstacles Duval put forward to hinder the development of digital publishing, especially language barriers, human factors and weak infrastructure, are the same in Mali. Among these obstacles, infrastructure is still a very big problem. In his paper, «De l'actualité et de la pérennité du livre à l'ère des TIC: Le Cas de l'Afrique» was published in the proceedings of the 50th anniversary seminar of "Africa", (Mbengue , 2018) defend the following ideas:

"There are two reasons for questioning the challenge of e-books in Africa. Either Africa finds itself in the reflex of survival in the face of Western domination, and the West produces a large amount of digital content and reading technology-"save itself or perish", or Adopt a method and strategic vision to enable African books to exist in the digital age."

Similarly, (Samba, 2018) think that this vision must integrate veritable digital publishing training: "The establishment of public, sub-public or private publishing structures has not improved this situation. Before 2018, Mali had no publishing training. Most local publishers have learned knowledge at work. In addition, today, many of them are converted writers, perhaps because they are disgusted with the country's lack of a real publishing house, because of the country's literature and knowledge. And scientific production is so important and appreciated that it has received great interest in Western countries."

According to Lareus Gangoueus in his article on the slow evolution of digital publishing in Africa, the 20 publishers responded to the survey of the promotion method of the e-book platform Reassi Ouabonzi, $60 \%$ gave a favorable public opinion digital collection but not assured method distribution program, Especially through cooperation with large platforms such as Google Books or Amazon. This explains why African publishers are reluctant to embark on digitization. The lack of training in electronic tools by publishers is also a hindrance. As far as the author is concerned, this distrust is becoming more and more serious, because the copyright linked to the ebook does not benefit from any legal framework. In fact, in most African countries, including Mali, there are still no legal regulations on e-books. Therefore, the authors did not know what to do and remained silent on the e-book. In Mali, the above-mentioned reality is the same, because digital publishing is still in its infancy. Therefore, in Mali, the possibilities offered by digital technology are unfortunately not immediately applicable due to the specific limitations of the local environment. 
According to a survey by Alliance-lab, 12 publishers in Africa (including Mali) have noticed that the transformation of the book industry faces many pitfalls:

$>$ Local professionals do not always have the necessary professional knowledge.

$>$ The publishing house's collection is not digitalized.

$>$ Piracy is rampant.

$>$ Lack of support from the public sector.

The software is too expensive.

Apart from the reluctance of the main players in this book, Mali does not have the necessary infrastructure to properly promote electronic publishing. The utilization rate of e-reading tools such as e-readers and tablets is still very low. Other issues are related to electronic publishing, and therefore also related to the promotion of electronic literature. These include:

\section{Insufficient power supply}

Insufficient power supply is also a factor that slows down the development of electronic publishing, which has attracted the attention of publishers and readers. In Africa, power outages are very frequent, and readers are not encouraged to obtain e-books. In more remote areas, especially rural areas, the situation is more serious because of power supply problems. However, without preconditions, it is impossible to use e-books.

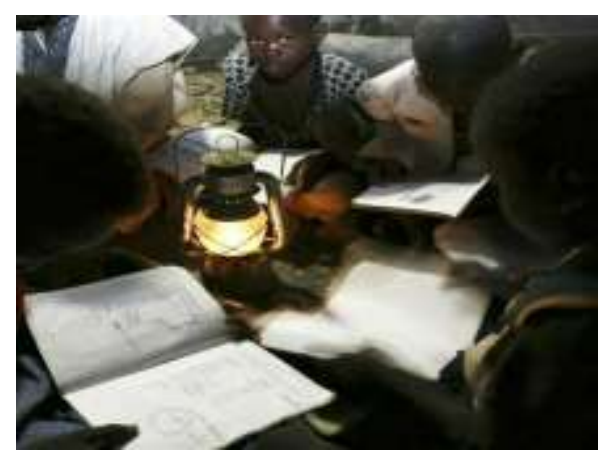

Fig (1) Illustrative imageMalian schoolchildren are lighting up with an oil lamp.

Sanogo / AFPSee:https://www.rfi.fr/fr/afrique/20130428electricite-societe-energie-mali-arrive-toujours-pas-repondredemande

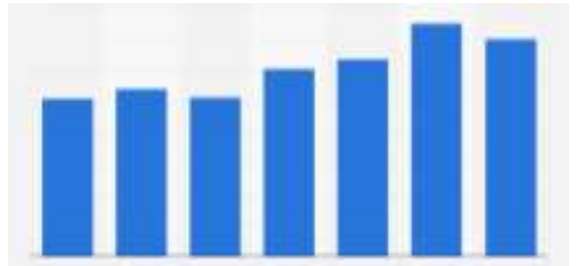

Fig(2) Insufficient power supply Static Statista

https://fr.statista.com/statistiques/955634/acces-electricitemali/

This statistic represents the share of the population with access to electricity in Mali from 2010 to 2016. In 2016, the rate of access to electricity in the country was around $35 \%$, compared to $25.4 \%$ in 2010 .

\section{Marketing of e-books}

In terms of e-book marketing, since e-books must be purchased online, the low rate of banking is also an obstacle for publishers. However, to make online shopping, you not only need to know how to operate, but most importantly, it is a complete computerized and coordinated system that combines the banking system with a developed and developed computer system. In addition, some people with bank accounts don't know how to pay online. Others worry about becoming the target of online fraud and would rather give up online payment.

\section{Audiobook}

In addition, audiobooks are also an important part of electronic literature, but in Mali, audiobooks are far from becoming mainstream. Although the characteristics of audiobooks are oral, and oral literature has developed well in Africa, especially in Mali, audiobooks are still an unacceptable fact.

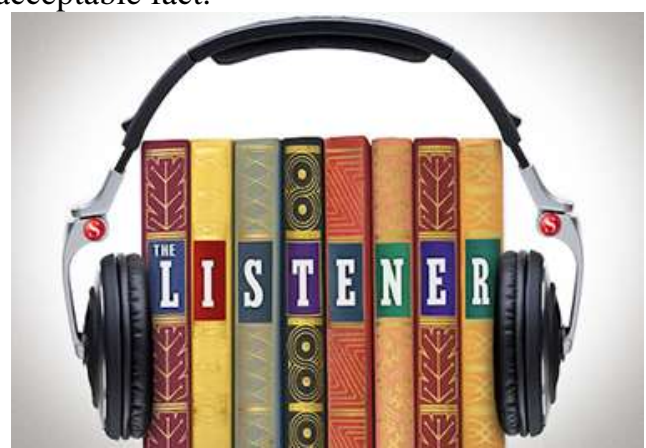

Fig (3) Source: Reading in the Digital Age: Audiobooks by Librivox

https://www.dwrl.utexas.edu/2016/12/01/reading-in-thedigital-age-audiobooks-by-librivox/

\section{Backward telecommunications infrastructure}

The classification category of the heavily indebted poor countries (debt), Mali (1241,000 square kilometers, $20,933,072$ residents according to 2020 statistics) is characterized by $80 \%$ of the population living in rural areas, in an unevenly distributed country (60\% of the land) Is the desert and sparsely populated north). $49 \%$ of Malians are under 15 years of age; the annual population growth rate is $3.7 \%$. The Human Development Index ranked 174th among 177 countries in the world (2003), and the Human Poverty Index ranked 93rd among 95 countries in the world. The annual gross national product and per capita are only 240 US dollars (compared to 24,000 US dollars in France and 30,000 US dollars in the United States). The economy is mainly based on agriculture-forest-animal husbandry. Industrialization is in its infancy. Due to lack of energy, the country mainly imports hydrocarbons. The specific territorial, climate, economic and demographic characteristics of Mali make the use of information and communication technology more difficult than the countries in the northern hemisphere, which are generally industrialized, affluent, urbanized and "densely populated". (Traoré, Djénéba, 2007)

In other words, promoting the development of electronic literature is inseparable from the construction of telecommunications infrastructure, and the construction of telecommunications infrastructure is a necessary condition to better promote this literary trend. The Internet, because 
it is indeed the latter, is the core to better and sustainably promote the field of electronic literature. With the rise of new information and communication technologies, it is becoming an inevitable daily trend.

\section{Internet access is still a long-standing problem}

When it comes to electronics, electronic publishing, and electronic literature itself, we must talk about the Internet. Without it, the promotion of electronic literature will be difficult. The Internet plays an important role in the field of electronic literature. The Internet provides African countries with numerous opportunities to obtain scientific and technological information. This is a way to strengthen their participation in the world economy, thereby benefiting their people in a universal and sustainable way. It is also a medium that can use the capabilities and knowledge of the African continent. (Omar Mimouni, 2001) When it comes to the Internet, the first question is whether it is easy for Internet users to access. However, this is not the case throughout Africa, especially in Mali. Access remains a key issue for information and communication technology in African countries, although the situation in each country is very different. The need for remote communication is everywhere, although different tools are needed in different places. The "electronic divide" is primarily geographical; it applies to all scales and models existing gaps. Some benchmarks allow us to locate the extent of the problem and the diversity of the situation according to the scale. On a global scale, Africa is still insignificant, and the gap with other continents is widening. The demand is high, but it is hindered by the lack of telephone infrastructure and their unequal distribution, which results in the Internet access rate being the highest in the world in terms of the number of telephone users. In 2021, Africa represents only $10.9 \%$ of Internet users in the world, or approximately 507.9 million Internet users on the continent.

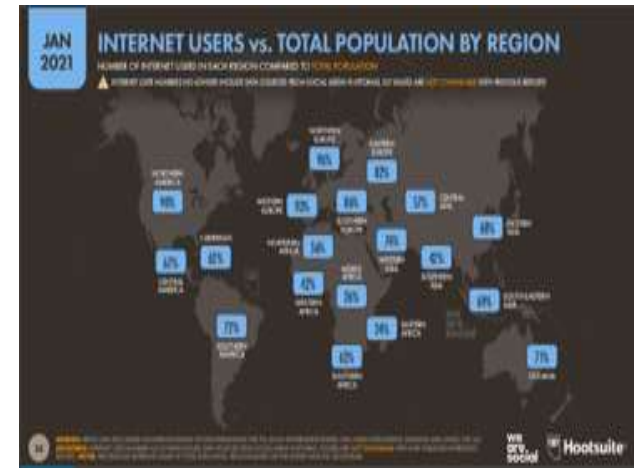

Fig. (3) Chiffres d'Internet en Afrique (2021)

In this image, it can be seen that West Africa's internet penetration rate is only $42 \%$. Out of 20.55 million inhabitants, there were only 5.74 million Internet users in Mali in January 2021. The number of Internet users in Mali increased by 895 thousand $(+18 \%$ ) between 2020 and 2021. Internet penetration in Mali was $27.9 \%$ in January 2021. 55.7\% of the Malian population lives in rural areas. There were 2.10 million social media users in Mali in January 2021. The number of social media users in Mali was equivalent to $10.2 \%$ of the total population in January 2021. Providing these numbers is important, useful and necessary. Indeed, in a section of this paper, a comparative analysis was carried out by speaking of the electronic literature in certain countries of the world. It is obvious that the penetration of the internet as well as the internet users are considerable. With regard to promoting electronic literature, it is undeniable that it remains important or even necessary for the country to have telecommunications infrastructure, on the other hand, network coverage must also be promoted as well as the facilitation of access to the Internet.

According to data from the International Telecommunication Union (ITU), the Internet exists in all countries, but its growth is slowing. International bandwidth connects telephone and Internet users in Africa with neighbor's around the world. It is provided by fibre optic cables, such as the existing South Atlantic 3/West Africa (SAT3/WASC) submarine cable, or by satellites. In order to use greater capacity, fibre optic is a more economical transmission method than satellites (although satellites are still the key to connecting rural areas).

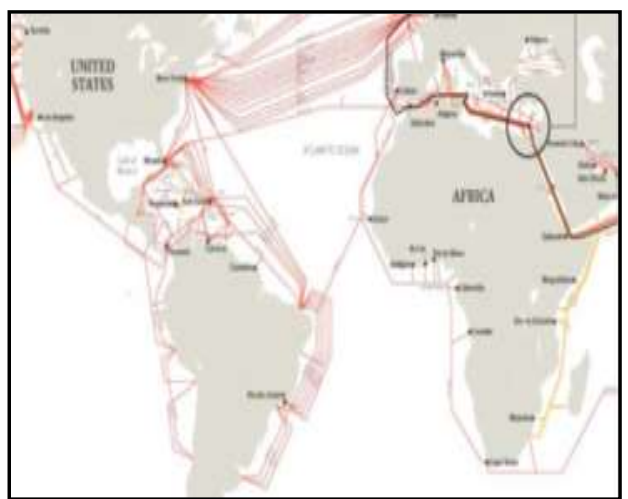

Fig. (4) fibre optic cables, such as the existing South Atlantic 3/West Africa (SAT3/WASC) (USAID)

\section{The brief origin of the Internet (historical reminder)}

Mali was connected to the Internet on December 31, 1996 due to the installation of the national Internet node CFAF cost 300 million, $50 \%$ by the current telecom operator, Société des télécommunications du Mali (SOTELMA) and the United States Agency for International Development (USAID) through the Leyland initiative . This node started operation on June 26, 1997, and was officially launched on September 20, 1997. After SOTELMA initiated a tender, four Internet Service Providers (ISPs) obtained market permits. The fifth PSI was approved in June 1999. However, in Mali, access to information and communication technology productsespecially the Internet is still extremely limited. According to data from the International Telecommunication Union (ITU), only $1 \%$ of Mali's population has access to the Internet, which is one of the countries with the lowest Internet access rate in Africa. According to a map made by two researchers at Oxford University in the UK, they pointed out that Africans are among the countries with the least Internet access. 


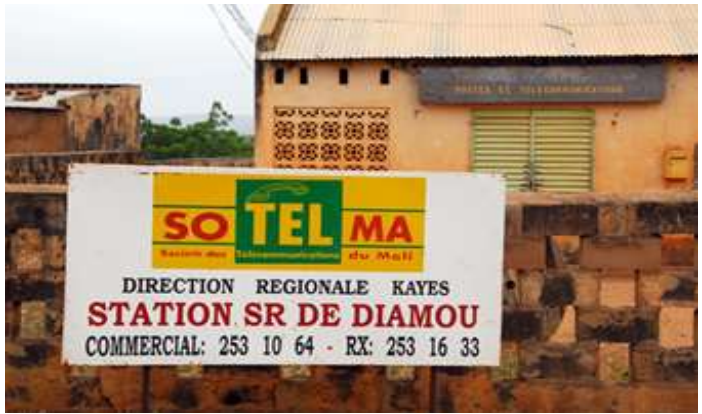

Fig. (5) Internet source, but inspire by the e-book by Naffet Keita entitled "Téléphonie et mobilité au Mali"

Ralph Strawman and Mark Graham used the 2013 World Bank Development Indicators and natural earth data to list all the countries in the world that are most disconnected from the Internet on a world map. They pointed out that without a critical value, people can consider Internet penetration to be sufficient, and they have done this work to determine who can access the Internet and who cannot. As a result, this map highlights most areas that have little Internet access, and, by extension, these areas are "largely away from participating in the cultural, educational, political, and economic activities supported by the tool." According to a study published on Geonet, the centre of poor Internet access is in sub-Saharan Africa. Researchers estimate that in the region, there are 28 countries with low Internet penetration rates, with the threshold below $10 \%$. In these countries, especially Mali, Internet access is still a major problem. Obviously, Mali still has a long way to go and needs to build telecommunications infrastructure in order to promote the promotion of electronic literature. Such as Western countries and China, they are doing correct development in electronic literature. Convenient access to the Internet is a necessary condition to achieve this goal, because all digital things are closely related to the convenient access to this tool (Internet), and it is more indispensable in all areas of life than ever before.

In addition, we hope that the "One Belt One Road" initiative can become Mali's main asset in order to promote its infrastructure, especially technology-related infrastructure. In fact, BRI basically brings together three related initiatives: the Silk Road Economic Belt, the Maritime Silk Road and, more recently, the Digital Silk Road. Along these corridors, many infrastructure projects are underway or planned, including pipelines, roads, railways, ports, digital networks (including 5G), and the promotion of massive industrial investment. However, although this insistence came a bit late, it is worth pointing out that the "Belt and Road" initiative will enable many countries, including Mali, to not only promote their economic growth. , But it can also make considerable contributions in many important sectors. $\mathrm{Xi}$ Jinping believes that Africa must use the "Belt and Road" project because "inadequate infrastructure is the main obstacle to Africa's development"-many African leaders agree with this view.

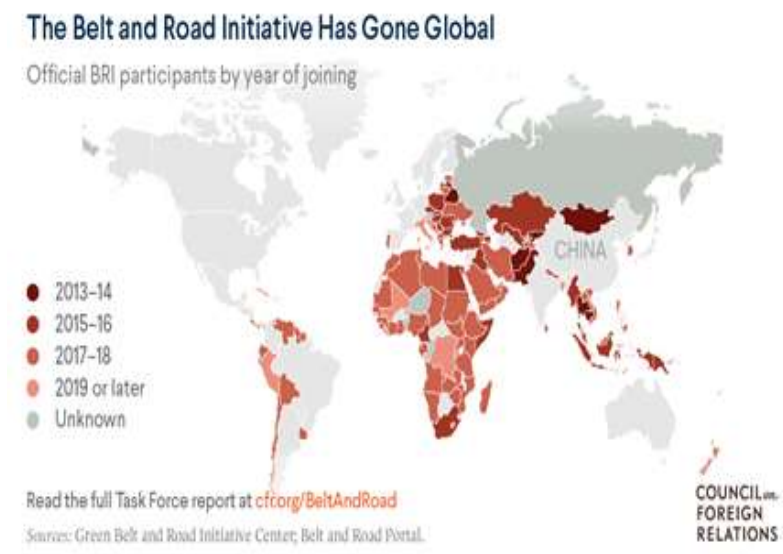

Fig. (6) Countries in China's Belt and Road Initiative: Who's In And Who's Out

https://www.cfr.org/blog/countries-chinas-belt-and-roadinitiative-whos-and-whos-out

\section{Conclusions}

Electronic literature has become a literary trend. The rise of new communication technologies has affected all areas of our lives. Obviously, in the field of education, we are talking about educational channels, especially literature. However, considering certain socioeconomic, geographic and technological factors, Mali is still at a standstill in the proper promotion of digital literature. In addition, in order to better promote this literary trend and sustainability, it is still necessary to implement the necessary and basic means, because this literary trend is promoted and developed in countries that implement these means including the development of telecommunications infrastructure, in order to Internet tools that make accessibility better and easier have become inevitable in our daily lives. In addition, in the body of the paper, we have dedicated a section to a comparative approach in which we have given some details on the advances of some in the field of electronic literature. Indeed, to situate what we want to highlight, it was important or even necessary to adopt this comparative approach insofar as to show how much Mali is lagging behind in this area. In all these countries, not only is the network coverage sufficient, access to the Internet is easy, the supply of electricity is sufficient, but also the authorities of these countries have made efforts to promote telecommunications infrastructures. Therefore, the promotion of electronic literature is also linked to these different factors.

\section{Recommendation}

$>$ It is imperative to promote electronic publishing. For traditional publishers still facing the cost of paper and the low number of bookstores in Africa, electronic publishing represents a real opportunity to provide them with good ICT training, partners in the public sector, cost reduction 
software or move towards free software and combat piracy s method.

$>$ The digitization of publishing house assets is still a prerequisite for urgent implementation. Mobile phones, which are experiencing rapid growth, seem to be an asset to be developed.

$>$ It is imperative to develop telecommunications infrastructure as a necessary condition for any digital activity.

$>\quad$ The utilization of internet must be easy. For this reason, the connection cost must be reduced to make it reasonable.

$>$ It is necessary to promote reading. In the context of electronic literature, audiobooks, as an important part of electronic literature, must be promoted vigorously.

$>\quad$ The opportunity to bring mobile phones into the library should be provided.

In addition, social networks that are widely used by young people are also necessary.

\section{Acknowledgments}

I would like to extend my sincere thanks to my supervisor who gave me relevant, useful and logical suggestions during the writing of this article.

\section{References}

[1] Rahman, F. (2017). Cyber literature: A readerwriter interactivity. International Journal of Social Sciences \& Educational Studies, 3(4), 156.

[2] Rucar, Y. (2015). La littérature électronique. Presses de l'Université de Montréal.

[3] Marino, M. C. (2008). The Electronic Literature Collection Volume I: A New Media Primer. Digital Humanities Quarterly, 2(1).

[4] Pawlicka, U. (2017). An Essay on Electronic Literature as Platform. Przegląd Kulturoznawczy, 33(3), 430-444.

[5] Rettberg, S. (2012). Developing an identity for the field of electronic literature: reflections on the electronic literature organization archives. Dichtung Digital, 41.

[6] Block, F. W. (2018). Electronic literature as paratextual construction. MATLIT: Materialidades da Literatura, 6(1), 11-26.

[7] Emerson, L. (2011). On E-Literature as a Field. Reading Writing Digital Textuality.

[8] Pawlicka, U. (2014). Towards a history of electronic literature. CLCWeb: Comparative Literature and Culture, 16(5), 2.

[9] Nelson, T. (1993). Literary Machines. Sausalitu, CA: Mindful press.

[10]Eskelinen, M. (2012). Cybertext Poetics: International Texts In Critical Media Aesthetics. New York: Continuum.

[11] Hooverm, D .L., Culpeper, J., \& O Halloran, K. (2014). Digital Literary Studies: Corpus
Approaches to Poetry, Prose, and Drama. New York: Routledge.

[12]Ryan, M. L. (2013). Fictional Worlds in the Digital Age. In Siemens, R. \& Schreibman, S. (Eds), A Companion to Digital Literary Studies. West Sussex. UK: Blackwell Publishing Ltd

[13] Sanz, A., \& Romero, D. (2007). Literatures in the Digital Era: Theory and Praxis. Newcastle: Cambridge Scholars Publishing.

[14]Hayles, K. (2001). Cyber literature and Multicourses: Rescuing Electronic Literature from Infanticide.

[15] Retrieved from < http://www.electronicbookreview.com/ thread/electropoetics/interspecial>

[16] Cissé, M. (2006). Écrits et écriture en Afrique de l'Ouest. Revue électronique internationale de sciences du langage Sudlangues, 6 .

[17] Alexandre, P. (1967), Langue et langage en Afrique noire, Paris, Payot, 169p. (Introduction)

[18] Terry Eagleton, \& Chen Jianhui. (1992), the definition of literature. Journal of Hainan Normal University: Social Science Edition (3), 131-136.

[19] Vaillancourt, M. (2020). Le numérisme: un objet religieux contemporain?.

[20] Vitali-Rosati, M. (2014). Pour une définition du" numérique". Pratiques de l'édition numérique, 63-75.

[21] Reclus, O. (1883). France, Algérie et colonies. Paris, France : Librairie Hachette.

[22] VITALI-ROSATI, Marcello (dir.) ; SINATRA, Michael E. (dir.) (2014 ), Pratiques de l'édition numérique. Nouvelle édition [en ligne]. Montréal : Presses de l'Université de Montréal, (généré le 10 décembre 2020).

[23] Vitali-Rosati, M. (2020). Qu'est-ce que l'écriture numérique?. Corela. Cognition, représentation, langage, (HS-33).

[24]Bennett, G. (2010). Ce livre qui n'en est pas un: le texte littéraire électronique. Littérature, (4), 37-43.

[25]Hayles, N. K (2008). Electronic literature. University of Notre Dame Press.

[26] Hicks, D (2008). Electronic literature: new horizons for the literary. Library Journal, 133(8), 66-66.

[27] Xu Tenglong, \& Hua Yan. (2020). A crosscultural perspective on the popularity of Chinese online literature overseas.

[28] Tuo Jiguang. (2017). The role and path of online literature in my country's "Cultural Going Global". Journal of Guangzhou University (Social Science Edition), 16(9), 86-91.

[29] Rettberg, S. (2009). Communitizing electronic literature. Digital Humanities Quarterly, 3(2).

[30] Taylor, C. (2019). Electronic Literature in Latin America: From text to hypertext. Springer Nature. 
[31]Dembele, Alexis(2015), « Parler comme un conte, ou l'art de transmettre la connaissance en Afrique », Hermès, La Revue, vol. 72, no. 2, pp. 243-249.

[32] Moustapha Mbengue, Moussa Samba(2020), Les enjeux et pratiques de l'édition numérique en Afrique : le cas du Sénégal. Mélanges offerts au Professeur Saliou Mbaye, itinéraire d'un militant de la mémoire africaine, Editions de l'EBAD, pp.77-90,

[33] Omar Mimouni (2001) , L’internet en Afrique, mise en évidence du raccourci technologique et étude d'impact, , page 6

[34] Keita, N. (2015). Téléphonie et mobilité au Mali. Langaa RPCIG. 